\title{
AVALIAÇÃO ERGONÔMICA DE CADEIRAS RESIDENCIAIS FABRICADAS NO PÓLO MOVELEIRO DE UBÁ, MG ${ }^{1}$
}

Patrícia Bhering Fialho ${ }^{2}$, Amaury Paulo de Souza ${ }^{3}$, Luciano José Minette ${ }^{4}$ e José de Castro Silva ${ }^{3}$

\begin{abstract}
RESUMO - Este trabalho teve como objetivo realizar uma "Avaliação ergonômica de cadeiras residenciais fabricadas no pólo moveleiro de Ubá, MG”, visando, assim, à melhoria da qualidade ergonômica dos móveis, bem como ao aumento da competitividade dos produtos oriundos desse pólo. A coleta de dados foi realizada em 15 cadeiras de 12 indústrias associadas ao Sindicato Intermunicipal das Indústrias de Marcenaria de Ubá - INTERSIND. Os critérios de conformidade ergonômica foram definidos de acordo com os princípios ergonômicos de antropometria e os aspectos de segurança para o usuário. Os resultados das medições foram confrontados com recomendações e dados antropométricos existentes na literatura. Observou-se que os maiores problemas detectados nas cadeiras estavam relacionados às dimensões do assento e à sua altura até o piso, em que $100 \%$ das cadeiras apresentaram alturas dos assentos superiores aos valores recomendados pela literatura. Os encostos não tinham problemas quanto à largura, porém necessitavam de adequação dos ângulos de inclinação em relação aos assentos. Outro aspecto observado foi a grande incidência de quinas e bordas retas, que podem ocasionar acidentes aos usuários desses móveis.
\end{abstract}

Palavras-chave: Cadeiras, móveis e ergonomia.

\section{ERGONOMIC EVALUATION OF RESIDENTIAL CHAIRS MANUFACTURED IN THE FURNITURE INDUSTRY OF UBÁ, MG}

\begin{abstract}
The objective of this work was to carry out ergonomic evaluation of residential chairs manufactured in the furniture industry of Ubá, MG, seeking improvement of ergonomic quality of the pieces of furniture, as well as the increase in competitiveness of the products originated from of this pole. Data was collected in 15 chairs from 12 industries associated with the Trade Union of Uba's furniture industry- INTERSIND. The criteria for ergonomic conformity were defined in agreement with the anthropometric principles of ergonomics and users safety aspects. The data obtained were compared with recommendations and anthropometrical data reported in the literature. The major problems detected in the chairs were related to seat dimensions and seat height from floor, in which $100 \%$ of the chairs presented seat heights higher than the recommended by the literature. The back portions showed no problems in relation to width, however the seat inclination angles must be adapted. Another observed aspect was the great number of corners and sharp edges that can cause accidents to users.
\end{abstract}

Keywords: Chairs, furniture and ergonomics.

\footnotetext{
${ }^{1}$ Recebido em 11.09.2006 e aceito para publicação em 20.03.2007.

${ }^{2}$ Programa de Pós-Graduação em Ciência Florestal da Universidade Federal de Viçosa (UFV). E-mail: <patbhering@ yahoo.com.br>.

${ }^{3}$ Departamento de Engenharia Florestal da UFV. E-mail: <amaurysouza@ ufv.br>.

${ }^{4}$ Departamento de Engenharia Elétrica e de Produção da UFV. E-mail: <minetti@ ufv.br>.
} 


\section{INTRODUÇÃO}

O desempenho das atividades do setor florestal passou por muitas mudanças nos últimos anos. A procura por maior competitividade, através da inovação no setor, resultou em novos processos de trabalho, aumentando o rendimento das operações (FIEDLER et al., 1998).

Acompanhando as mudanças no setor florestal, o setor moveleiro também evoluiu, com a utilização de novas matérias-primas (Aglomerado, MDF, OSB) e novos processos para fabricação de móveis. Adicionado a isso, os consumidores, mais exigentes quanto à qualidade dos produtos, procuram por móveis que apresentem, além componente "estético", aspectos de segurança, saúde, durabilidade, funcionalidade, resistência, adaptação antropométrica e certificação, que pode estar presente desde a matéria-prima, com o uso da madeira certificada, até o atendimento das normas técnicas.

Uma das formas usadas para avaliar um móvel é proceder-se a uma avaliação da sua conformidade, seguindo procedimento e critérios estabelecidos em norma-padrão. No Brasil, normalmente são utilizados os procedimentos descritos em ABNT ISO/IEC, citada pelo INMETRO (2005).

Segundo Iida (1990), o uso inadequado e produtos mal projetados podem causar sérios problemas à saúde do consumidor; preferencialmente, essas condições deveriam ser pensadas na fase inicial de cada projeto, diminuindo, assim, os problemas futuros na hora do uso.

Comumente os princípios ergonômicos são mais aplicados ao mobiliário de escritório, porém, igualmente, torna-se necessária a sua aplicação ao mobiliário doméstico. E, dentro desse ambiente, a cadeira destacase como um dos mobiliários mais utilizados. Entretanto, apesar da sua importância na vida diária das pessoas, no Brasil não existem normas técnicas direcionadas às cadeiras para uso residencial. A NBR 12666/1992 define cadeiras como "assento de espaldar para uma pessoa, com ou sem apoio nos braços".

Os modelos de cadeiras fabricadas no pólo moveleiro de Ubá, MG, são bastante variados. Cada empresa fabrica uma linha específica, com formatos, tamanhos, cores e materiais diferentes. Os critérios ergonômicos de fabricação deste móvel deveriam atender não somente às características antropométricas e biomecânicas dos usuários, mas, também, ao seu uso funcional, com a possibilidade do uso não-funcional.
A cadeira deve permitir, além da postura correta, mudanças de posição do usuário, uma vez que, como relatou Grandjean (1982) apud Fiedler et al. (1999), a adoção de posturas incorretas pode acarretar diversos problemas, como lesões nos músculos e tensões, aparecimento de fadiga física, câimbras, dores musculares e tremores.

Panero e Zelnik (2002) apontaram que uma das principais dificuldades em projetos de cadeiras é o fato de que o sentar-se é comumente visto como atividade estática, enquanto, na realidade, ela é dinâmica. Assim, é essencial que sejam utilizados dados antropométricos adequados, para se obterem as medidas e os espaços livres necessários para a movimentação do usuário.

O Brasil possui poucas publicações de dados antropométricos dinâmicos e funcionais da população. As medidas antropométricas são dados de base, essenciais para a concepção ergonômica de produtos industriais, sejam estes bens de capital ou de consumo (INT, 1988). Para aplicar corretamente os dados, é importante que sejam avaliados os fatores que influenciam os dados antropométricos, a exemplo de raça, etnia, dieta, saúde, atividade física, postura, posição do corpo e vestuário, entre outros.

Gomes (2003) citou que na determinação das dimensões de cadeiras residenciais, por serem assentos de menor permanência, é recomendada a utilização das dimensões corporais de um usuário com percentil 50.

A carência de dados antropométricos relativos à população brasileira e a falta de normas técnicas nacionais relacionadas a cadeiras de uso doméstico reforçam a importância do desenvolvimento de projetos com a finalidade de propor critérios de avaliação da conformidade, contribuindo para o desenvolvimento do setor moveleiro e para a melhoria do mobiliário fabricado. Com isso, agregar-se-ia mais um item de valor ao produto: a "qualidade ergonômica", que demonstra, dentro dos seus princípios básicos, como a segurança, o bem-estar e a satisfação do ser humano, soluções práticas para o desenvolvimento de móveis que sejam ergonomicamente adaptados a seus usuários e adequados à sua utilização diária.

Este trabalho teve como objetivo realizar uma avaliação ergonômica de cadeiras residenciais fabricadas no Pólo Moveleiro de Ubá, MG, visando, assim, à melhoria da qualidade desses móveis, bem como ao aumento na competitividade dos produtos oriundos desse pólo moveleiro. 


\section{MATERIAL E MÉTODOS}

Os dados foram coletados em 15 cadeiras de 12 indústrias associadas ao Sindicato Intermunicipal das Indústrias de Marcenaria de Ubá - INTERSIND, no período de outubro de 2004 a fevereiro de 2005.

Foram escolhidos para este trabalho os modelos de cadeiras de uso residencial mais vendidos de cada indústria, visando, assim, abranger maior representatividade das cadeiras para uso doméstico disponíveis no mercado.

Os critérios de conformidade ergonômica foram definidos de acordo com os princípios ergonômicos de antropometria e os aspectos de segurança. Os principais itens de avaliação ergonômica utilizados neste estudo foram: dimensões (comprimento, largura e altura), inclinação entre o assento e o encosto, presença de espaço livre entre assento-encosto, tipo de borda anterior do assento, estabilidade e presença de quinas e bordas retas.

As dimensões dos móveis foram obtidas por meio de medições diretas, utilizando-se instrumentos como goniômetro, trenas graduadas e fitas métricas. As dimensões avaliadas nas cadeiras estão representadas na Figura 1.

\section{RESULTADOS E DISCUSSÃO}

Os dados obtidos na coleta foram confrontados com as recomendações de Panero e Zelnik (2002), Gomes (2003) e com dados antropométricos do INT (1995).

A escolha da utilização do banco de dados do INT (1995) deu-se por ser este, atualmente, a base mais completa de dados antropométicos disponível da população brasileira.

Também foram encontrados dados antropométricos de 86 marceneiros de Viçosa, MG, publicados por Silva et al. (2001). Contudo, essa coleta tratava apenas de dados masculinos, sendo, assim, insuficiente para este trabalho.

Para efeito de comparação, as dimensões dos móveis atenderam às principais variáveis antropométricas, como: altura popliteal; largura do quadril, profundidade nádegapoplíteal para pessoa sentada, inclinação de conforto do tronco e largura do tórax (Quadro 1).

\subsection{Dimensões, detalhes de acabamento e estrutura}

\subsection{Assento}

\section{Altura do assento em relação ao piso}

O Quadro 2 apresenta os valores das alturas dos assentos recomendados por Panero e Zelnik (2002) e Gomes (2003) e valores com base em dados antropométricos do INT (1995).

Entre as amostras de assentos das cadeiras analisadas, observou-se que as suas alturas em relação ao piso variaram de $46,0 \mathrm{~cm}$ a $52,5 \mathrm{~cm}$, o que corresponde a uma amplitude de $6,5 \mathrm{~cm}$. Através da Figura 2, verificouse que $100 \%$ das cadeiras apresentaram alturas dos assentos superiores aos valores recomendados por Panero e Zelnik (2002) e por Gomes (2003) e ao valor referente ao dado antropométrico do INT (1995), relativo à altura popliteal de mulheres com percentil 50.

Figura 1 - Dimensões avaliadas em cadeiras. Figure 1 -Evaluated chair dimensions.

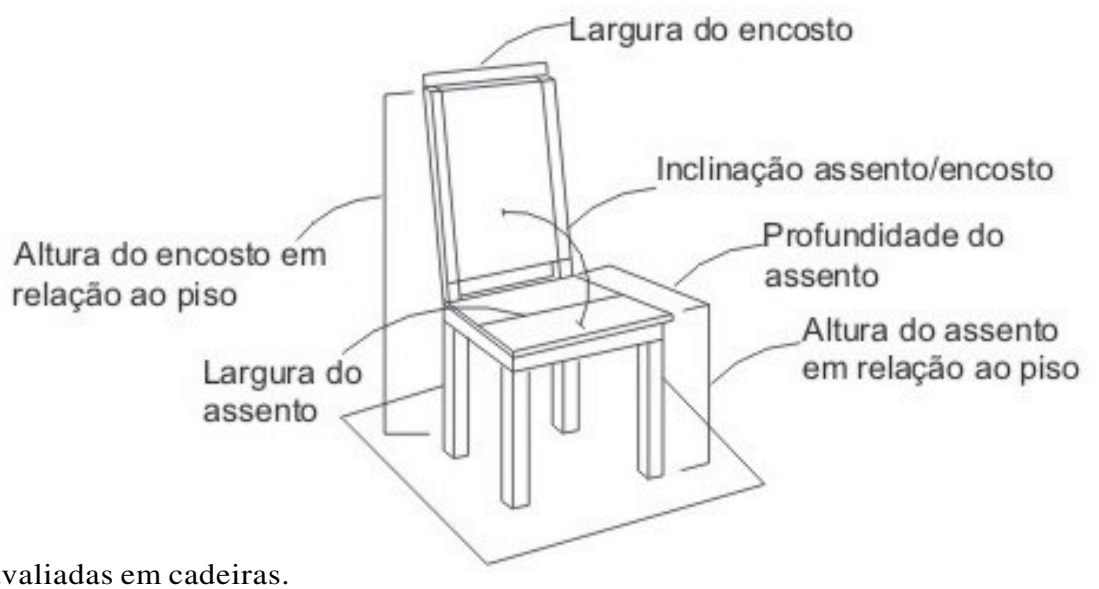


Quadro 1 - Variáveis antropométricas utilizadas no trabalho Table 1 -anthropometrics variables used in the work

\begin{tabular}{|c|c|c|}
\hline Medidas antropométricas & Descrição & Figura \\
\hline Altura popliteal & Distância vertical da curva interna do joelho (poplíteo) ao solo. & \\
\hline $\begin{array}{l}\text { Profundidade nádega } \\
\text { - popliteal, sujeito sentado }\end{array}$ & $\begin{array}{l}\text { Distância póstero-anterior do plano mais posterior das } \\
\text { nádegas (zonale glutae) à curva interna do joelho (poplíteo). }\end{array}$ & \\
\hline $\begin{array}{l}\text { Largura do quadril, } \\
\text { sujeito sentado }\end{array}$ & $\begin{array}{l}\text { Distância horizontal entre as superfícies mais laterais do corpo, } \\
\text { ao nível dos trocanteres maiores (entre a zonale glutae laterale } \\
\text { direita e a zonale glutae laterale esquerda), sujeito sentado. }\end{array}$ & \\
\hline $\begin{array}{l}\text { Largura do tórax entre } \\
\text { as axilas, sujeito sentado }\end{array}$ & $\begin{array}{l}\text { Distância horizontal entre as axilas (entre o axillare direito } \\
\text { e o axillare esquerdo). }\end{array}$ & \\
\hline $\begin{array}{l}\text { Inclinação de conforto } \\
\text { do tronco }\end{array}$ & Ângulo de inclinação do tronco para trás & \\
\hline
\end{tabular}

Quadro 2 - Valores da altura do assento das cadeiras, com base no dado antropométrico do INT (1995) e recomendações de autores

Table 2 -Seat heights of chairs based on anthropometric data by INT (1995) and the authors' recommendations

\begin{tabular}{lc}
\hline Autores e Entidades & Altura recomendada (cm) \\
\hline Panero e Zelnik (2002) & 40,6 a 41,3 \\
Gomes (2003) & 40,0 a 43,0 \\
Altura popliteal de mulheres com percentil 50, considerando 2,5 cm de acréscimo & 41,0 \\
devido aos sapatos, com base em dado antropométrico do INT (1995). & \\
\hline
\end{tabular}

A partir desses resultados, constatou-se que as elevadas alturas dos assentos, além de acarretarem desperdício da matéria-prima utilizada na fabricação desses móveis, podem causar diversos problemas aos usuários. Tais problemas, segundo Panero e Zelnik (2002), seriam, por exemplo, o desconforto, a má postura e a dificuldade de circulação sangüínea na parte interna das coxas.

Para Dul e Weerdmeester (1994), a altura adequada do assento é aquela em que a coxa está bem apoiada nele, sem esmagamento de sua parte inferior (em contato com as bordas do assento), e os pés se apóiam no piso, uma vez que a postura com os pés em balanço é muito fatigante. Para Panero e Zelnik (2002), se a altura do assento for muito baixa, os pés podem perder estabilidade pelo fato de as pernas terem de ficar estendidas à frente. Uma pessoa mais alta, no entanto, sentir-se-á mais confortável, usando uma cadeira com assento baixo do que uma pessoa baixa, usando uma cadeira com assento muito alto.

\section{Profundidade do assento}

O Quadro 3 apresenta as profundidades para assentos, recomendadas por Panero e Zelnik (2002), e valores com base nos dados antropométricos do INT (1995), relativos ao comprimento nádega-popliteal de mulheres com percentil 50 e percentil 5 .

Ao analisar os dados contidos neste trabalho, observou-se que as profundidades dos assentos variaram entre $35,0 \mathrm{~cm}$ e $50,0 \mathrm{~cm}$, o que corresponde a uma amplitude de $15,0 \mathrm{~cm}$. 


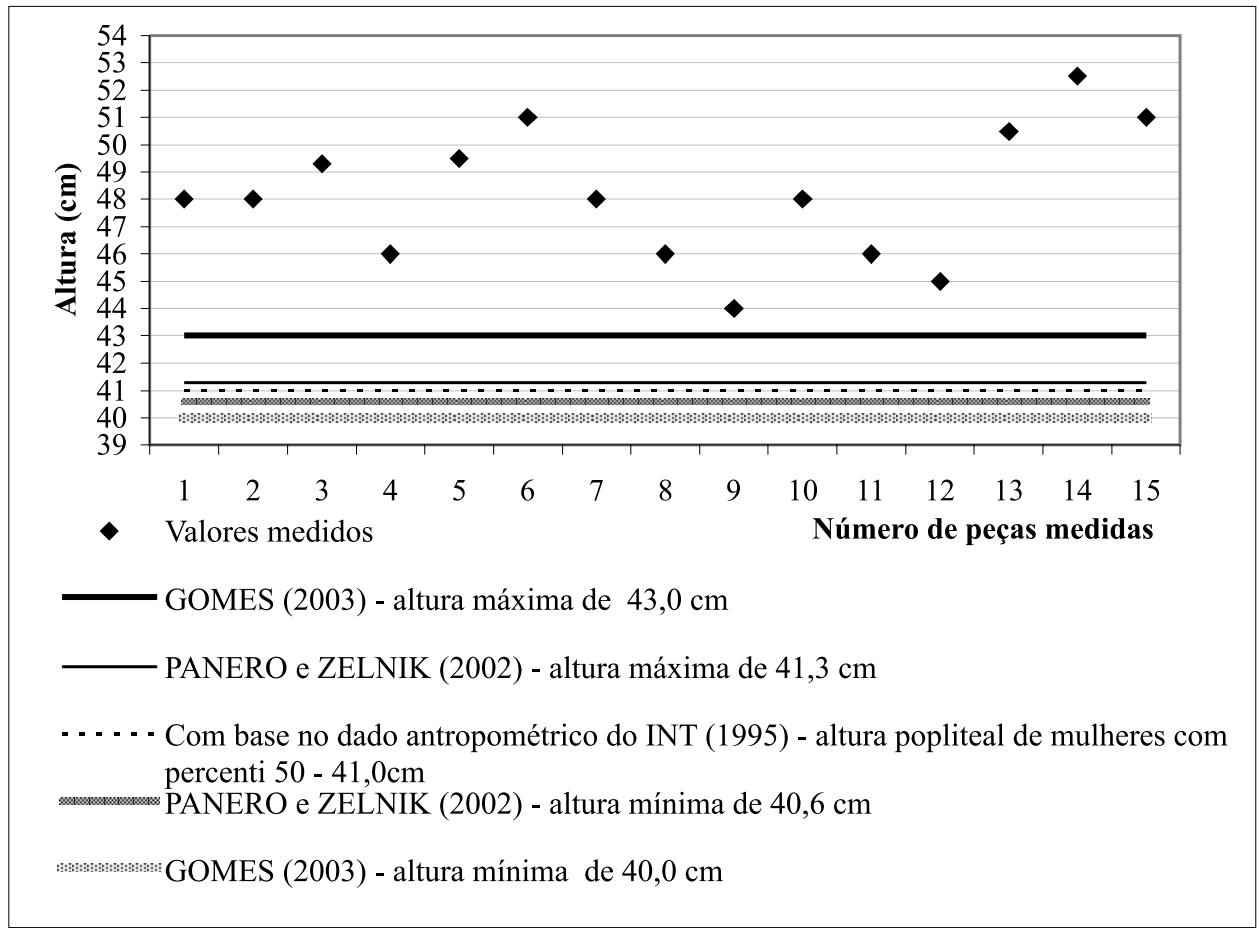

Figura 2 - Comparação entre os valores das alturas dos assentos e os valores referentes ao dado antropométrico do INT (1995) e as recomendações de Panero e Zelnik (2002) e Gomes (2003).

Figure 2 - Comparison between the seat heights and anthropometric data by INT (1995) and the recommendations by Panero and Zelnik (2002) and Gomes (2003).

Quadro 3 - Valores da profundidade do assento das cadeiras, com base em dados antropométricos e recomendação de autores Table 3 - Seat depths of chairs based on anthropometric data and the authors' recommendations

Autores e Entidades

Panero e Zelnik (2002)

Comprimento nádega - popliteal de mulheres com percentil 5, com

base em dados antropométricos do INT (1995)

Comprimento nádega - popliteal de mulheres com percentil 50, com

base em dados antropométricos do INT (1995)
Profundidade do assento recomendada $(\mathrm{cm})$

39,4 a 40,6

40,5

45,7
Quando comparados esses valores com os dados antropométricos do INT (1995), observou-se que 6,7\% das cadeiras não atenderam ao valor relacionado ao percentil 5, uma vez que apresentaram profundidades inferiores a 40,5 cm. Quando comparados esses mesmos valores com o percentil 50, verificou-se que $93,3 \%$ das cadeiras não atenderam a esse dado, posto que apresentaram profundidades dos assentos inferiores a $45,7 \mathrm{~cm}$.

Também, neste trabalho observou-se que 26,6\% das cadeiras não atenderam às recomendações de Panero e Zelnik (2002), uma vez que apresentaram profundidades dos assentos inferiores a $39,4 \mathrm{~cm}$.

Segundo Panero e Zelnik (2002), os assentos com muita profundidade podem causar compressão nos tecidos e gerar desconforto ao usuário. Já os assentos com pouca profundidade podem causar falta de suporte na parte inferior das coxas, dando a sensação de que o usuário está caindo do assento.

As comparações entre os valores medidos e os recomendados podem ser mais bem visualizadas na Figura 3.

R. Árvore, Viçosa-MG, v.31, n.5, p.887-896, 2007 


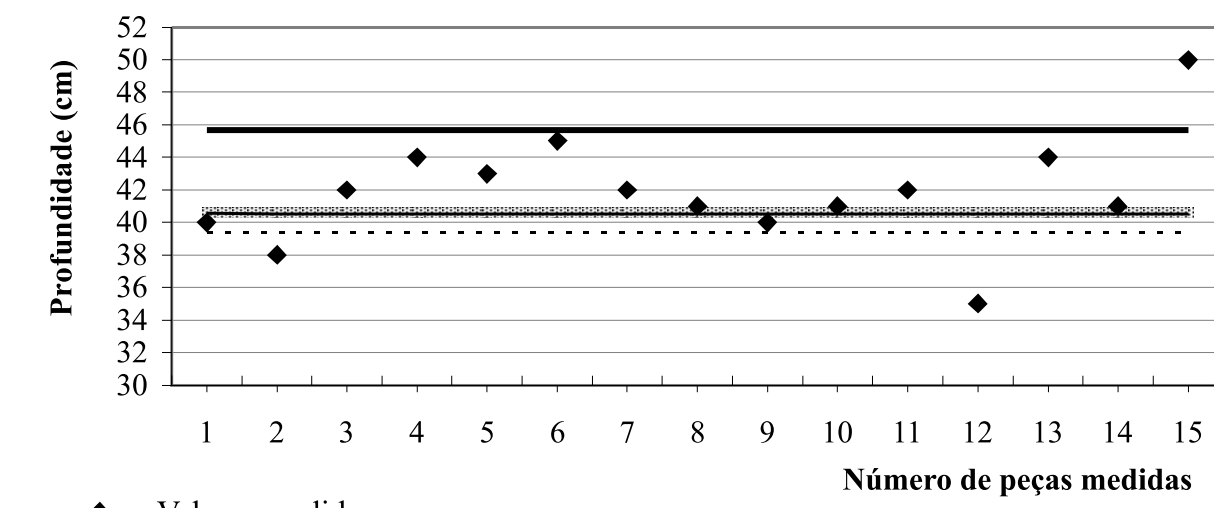

- Valores medidos

Com base em dado antropométrico do INT (1995) relativo ao comprimento nádega popliteal de mulheres com percentil $50-45,7 \mathrm{~cm}$

m:s:s: PANERO e ZELNIK (2002) - profundidade máxima de $40,6 \mathrm{~cm}$

Com base em dado antropométrico do INT (1995)relativo ao comprimento nádega popliteal de mulheres com percentil $5-40,5 \mathrm{~cm}$

- . - . - PANERO e ZELNIK (2002) - profundidade mínima de 39,4 cm

Figura 3 - Comparação entre os valores das profundidades dos assentos e os valores referentes aos dados antropométricos do INT (1995) e as recomendações de Panero e Zelnik (2002).

Figure 3 - Comparison between seat depths and anthropometric data by INT (1995) and recommendations by Panero and Zelnik(2002).

\section{Largura do assento}

O Quadro 4 apresenta as recomendações de Panero e Zelnik (2002) e os valores com base em dados antropométricos do INT (1995), quanto à largura do quadril de mulheres com percentis 50 e 95.

Considerando os assentos das cadeiras analisados, observou-se que as larguras deles variaram entre 36,0 $\mathrm{cm}$ e $44,0 \mathrm{~cm}$, o que equivale a uma amplitude de $8,0 \mathrm{~cm}$.

Através da Figura 4, verificou-se que 53,3\% das cadeiras apresentaram largura do assento entre as recomendações de Panero e Zelnik (2002). Observouse, também, que $86,7 \%$ das cadeiras atenderam ao valor referente ao dado antropométrico do INT (1995) para largura do quadril de mulheres com percentil 50, uma vez que exibiram valores das larguras dos assentos superiores a este dado antropométrico. Verificou-se, ainda, que $6,7 \%$ das cadeiras atenderam ao valor referente ao dado antropométrico do INT (1995) para largura do quadril de mulheres com percentil 4 , as quais apresentaram valores das larguras dos assentos superiores a esse dado antropométrico.

Quadro 4 - Larguras dos assentos, com base em dados antropométricos e em recomendação de autores Table 4 - Seat widths based on anthropometrics data and authors' recommendation

\begin{tabular}{lc}
\hline Autores e Entidades & Largura de assento recomendada (cm) \\
\hline Panero e Zelnik (2002) para cadeira polivalente (uso múltiplo). & $40,6-43,2$ \\
Largura do quadril de mulheres com percentil 50, com & 38,3 \\
base em dados antropométricos do INT (1995). & 45,4 \\
Largura do quadril de mulheres com percentil 95, com & \\
base em dados antropométricos do INT (1995). &
\end{tabular}

R. Árvore, Viçosa-MG, v.31, n.5, p.887-896, 2007 


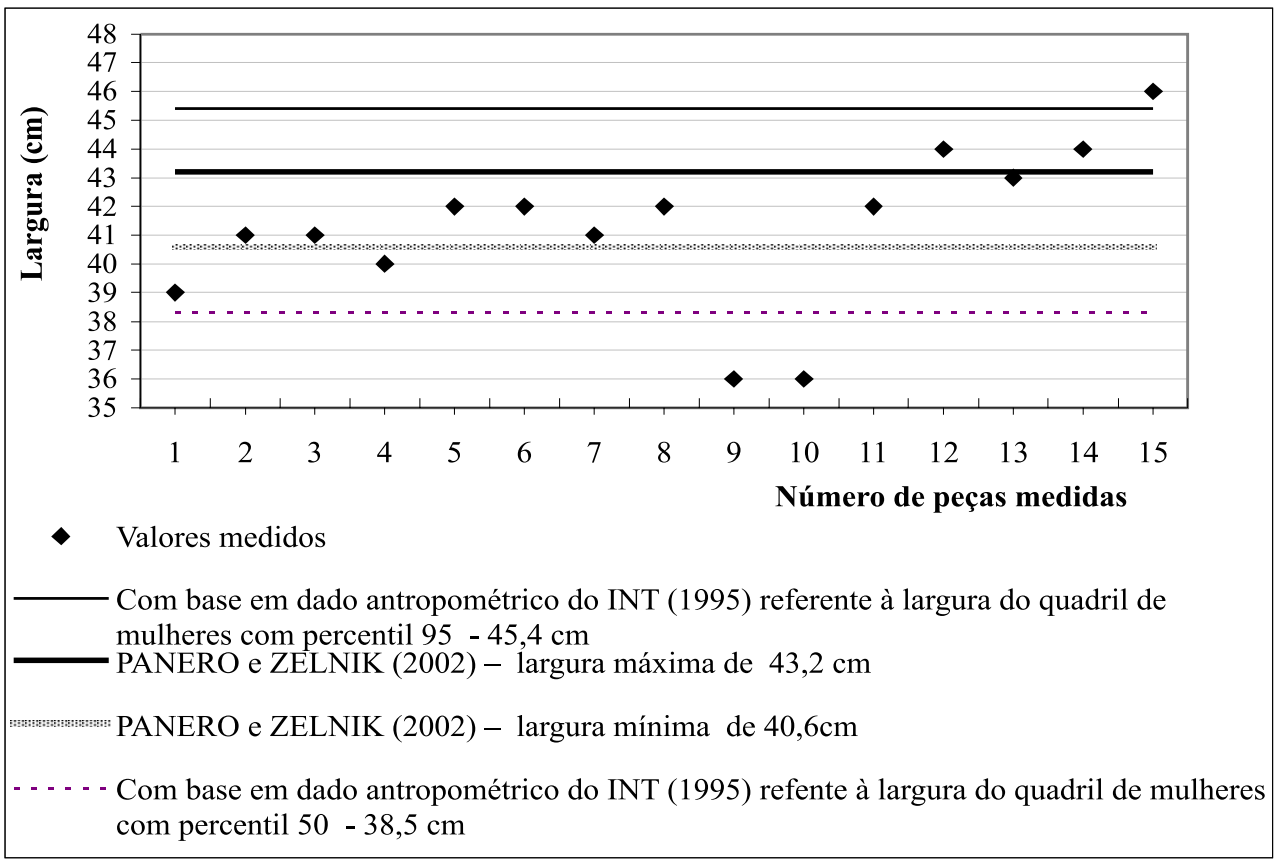

Figura 4 - Comparação entre os valores das larguras dos assentos e os valores referentes aos dados antropométricos do INT (1995) e as recomendações de Panero e Zelnik (2002).

Figure 4-Comparison between the seat widths and anthropometric data by INT (1995) and the recommendations by Panero and Zelnik (2002).

\subsection{Encosto}

Segundo Panero e Zelnik (2002), "o encosto da cadeira deveria permitir o apoio da região lombar". Observou-se, no entanto, que faltam publicações de dados antropométricos sobre essa região, que poderiam auxiliar a comparação com os dados adquiridos na coleta de dados.

Na realização deste trabalho, foram encontradas somente duas recomendações relacionadas com encostos, referentes à sua largura e altura em relação ao piso.

\section{Altura de encosto em relação ao piso}

Panero e Zelnik (2002) recomendaram que para cadeiras de múltiplo uso, com curto período de tempo, a altura do assento ao piso deveria variar entre 78,7 $\mathrm{cm}$ e $83,8 \mathrm{~cm}$.

Os encostos das cadeiras analisadas apresentaram alturas em relação ao piso entre $88,0 \mathrm{~cm}$ e $119,0 \mathrm{~cm}$, com uma variação de $31,0 \mathrm{~cm}$. Através da Figura 5, observa-se que $100 \%$ das cadeiras apresentaram altura de encosto superior às recomendações de Panero e Zelnik (2002).

\section{Largura do encosto}

De acordo com os resultados, observou-se que as larguras dos encostos variaram de $36,0 \mathrm{~cm}$ a 47,3 $\mathrm{cm}$, o que equivale a uma amplitude de $11,3 \mathrm{~cm}$.

Ao comparar esses valores com o valor referente ao dado antropométrico do INT (1995), relativo à largura do tórax entre as axilas, para homens com percentil $50(34,9 \mathrm{~cm})$, observou-se que $100 \%$ dos encostos atenderam a esse valor, uma vez que apresentavam largura superior a $34,9 \mathrm{~cm}$.

Quando comparados estes mesmos valores de larguras dos encostos com o dado antropométrico, relativo à largura do tórax entre as axilas de homens com percentil $95(39,1 \mathrm{~cm})$, observou-se que 92,9\% dos encostos estavam de acordo com este dado, uma vez que apresentaram largura superior a 39,1 $\mathrm{cm}$. As comparações realizadas estão representadas da Figura 6.

R. Árvore, Viçosa-MG, v.31, n.5, p.887-896, 2007 


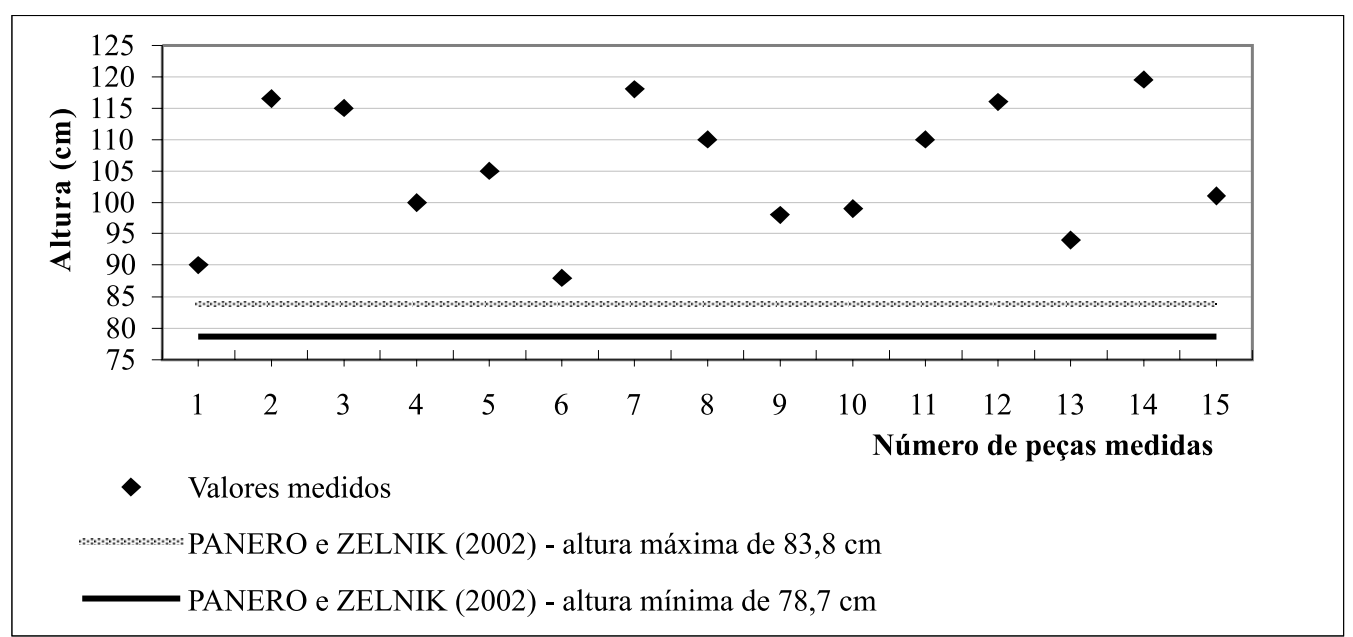

Figura 5 - Comparação entre os valores das alturas dos encostos ao piso e as recomendações de Panero e Zelnik (2002). Figure 5-Comparison between heights of back portions from floor and the recommendations by Panero and Zelnik (2002).

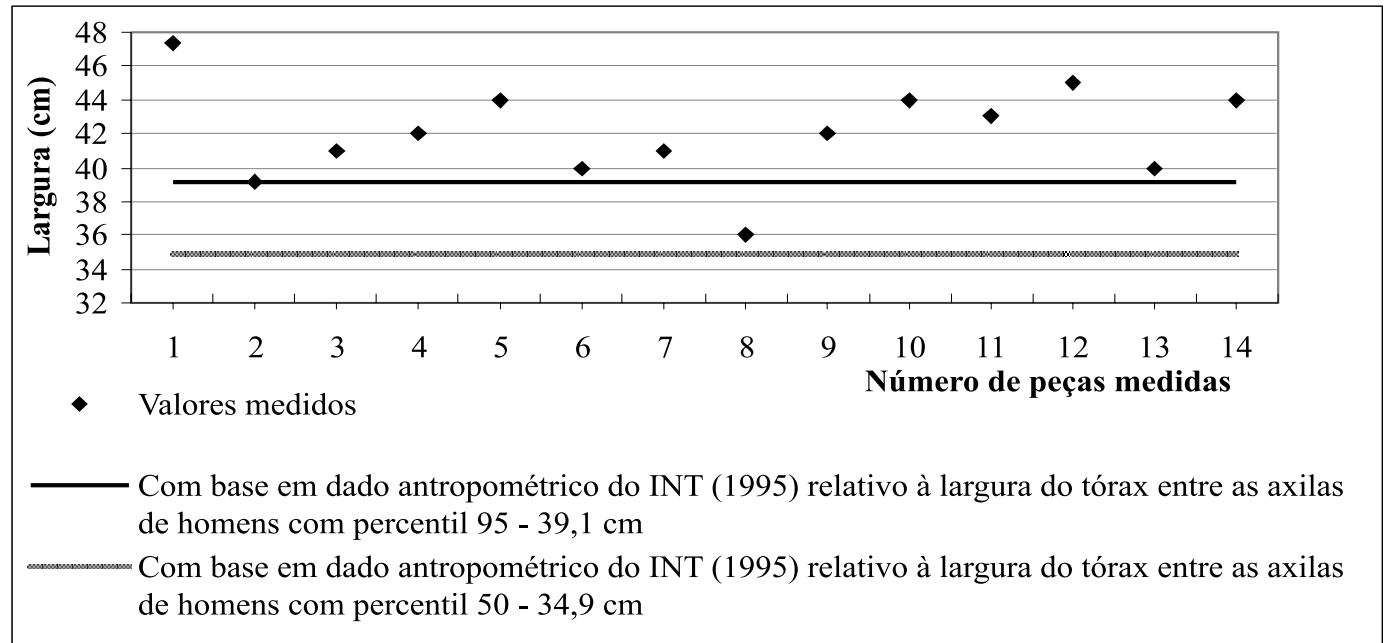

Figura 6 - Comparações entre os valores das larguras dos encostos e valores referentes aos dados antropométricos do INT (1995). Figure 6-Comparisons between widths of back portions and anthropometric data by INT (1995).

\section{Espaço livre entre assento e encosto}

Ao analisar as cadeiras, observou-se que $28,6 \%$ apresentaram espaço livre entre o assento e o encosto. A distância desse espaço variou entre $3,0 \mathrm{~cm}$ e $11,4 \mathrm{~cm}$.

\section{Inclinação do encosto}

Panero e Zelnik (2002) recomendaram que os ângulos de inclinações entre o assento e o encosto das cadeiras de múltiplo uso deveriam ser de $105^{\circ}$. Gomes (2003) sugeriu este ângulo de inclinação para conforto de cadeiras residenciais estivesse entre $95^{\circ}$ e $105^{\circ}$.

As cadeiras analisadas apresentaram inclinações de encosto, em relação ao assento, entre $90^{\circ}$ e $110^{\circ}$. Através da Figura 7, verificou-se que 9,1\% dos encostos analisados estavam de acordo com as recomendações de Panero e Zelnik (2002), uma vez que apresentaram inclinações iguais a $105^{\circ}$. Verificou-se, também, que $54,5 \%$ desses encostos estavam de acordo com as recomendações de Gomes (2003), com inclinações entre $95^{\circ}$ e $110^{\circ}$.

R. Árvore, Viçosa-MG, v.31, n.5, p.887-896, 2007 


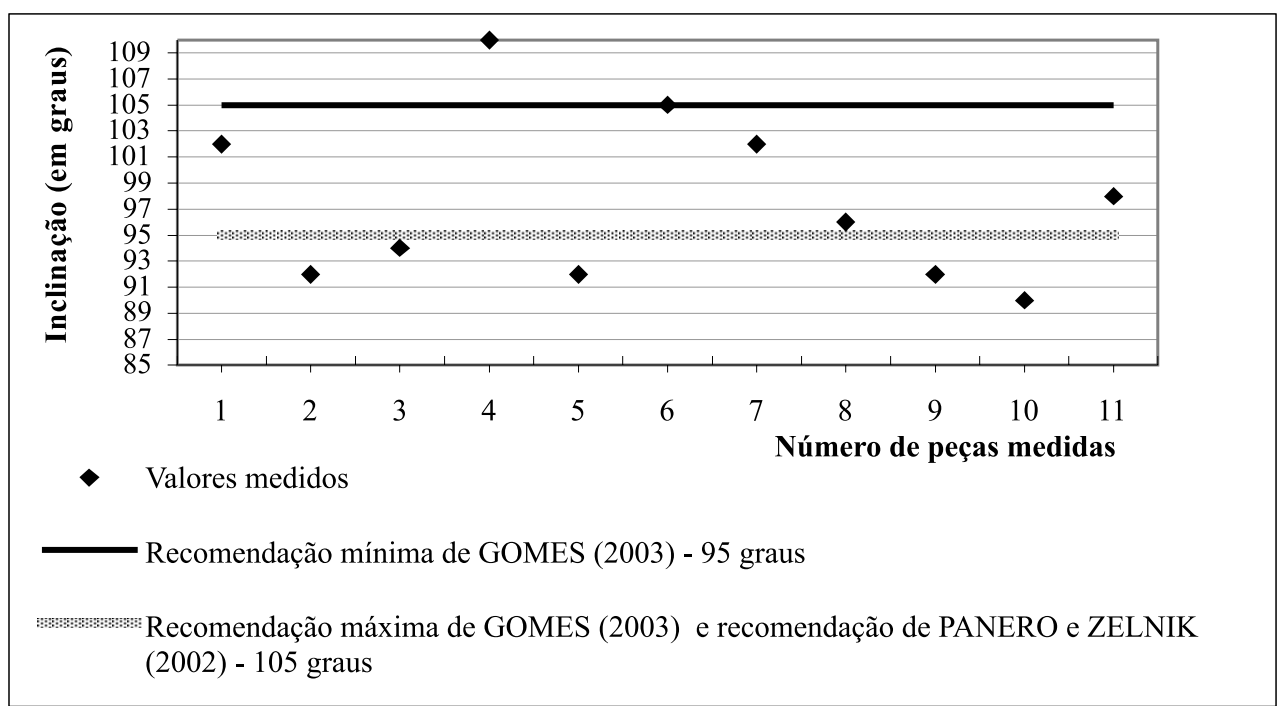

Figura 7 - Comparações entre os valores das inclinações dos encostos em relação aos assentos e as recomendações de Panero e Zelnik (2002) e Gomes (2003).

Figure 7 - Comparisons between the angle of inclination of the back portion in relation to the seat and the recommendations by Panero and Zelnik (2002) and Gomes (2003).

Ainda, segundo Panero e Zelnik (2002), ângulos de assento e encosto diferentes de $105^{\circ}$ podem ser prejudiciais ao usuário, uma vez que ângulos menores que este valor poderiam causar desconforto; ângulos maiores poderiam prejudicar os movimentos dos usuários para sentar-se e levantar-se das cadeiras.

\subsection{Aspectos de segurança}

Os aspectos de segurança foram tratados neste trabalho, enfatizando a presença de quinas e bordas retas e a estabilidade do móvel.

\section{Quinas e bordas}

Entre as cadeiras analisadas, 46,6\% apresentaram quinas retas e $20 \%$, bordas retas. Neste trabalho, este aspecto é considerado negativo, uma vez que quinas e bordas retas podem causar acidentes domésticos, prejudicando os usuários desse tipo de mobiliário.

\section{Estabilidade}

Em relação à estabilidade, observou-se que 6,6\% das cadeiras não eram estáveis, apresentando "balanço" ao sentar.

\section{Borda anterior do assento}

Entre as cadeiras analisadas, verificou-se que 7,1\% não possuíam bordas anteriores de assentos arredondadas. Apesar de aparecer em porcentagem baixa, este aspecto é considerado negativo, do ponto de vista ergonômico, pois, como citaram Panero e Zelnik (2002), bordas retas de assentos podem causar, além de um desconforto, compressão dos tecidos internos e, conseqüentemente, diminuição da circulação sanguínea na parte inferior da coxa.

\section{CONCLUSÕES}

Os maiores problemas detectados nas cadeiras avaliadas estavam relacionados às dimensões do assento e à sua altura até o piso. Os encostos não apresentaram problemas quanto à sua largura, porém necessitavam de adequação dos ângulos de inclinação em relação aos assentos.

Outro aspecto observado foi a grande incidência de quinas e bordas retas que podem ocasionar acidentes aos usuários desses móveis.

\section{AGRADECIMENTOS}

Os autores agradecem a colaboração das seguintes instituições: Departamento de Engenharia Florestal da Universidade Federal de Viçosa, FAPEMIG, CAPES, CNPq e INTERSIND.

R. Árvore, Viçosa-MG, v.31, n.5, p.887-896, 2007 


\section{REFERÊNCIAS}

ASSOCIAÇÃO BRASILEIRA DE NORMAS TÉCNICAS - ABNT. NBR 12666: Móveis. Rio de Janeiro: 1992.

COUTO, H. A. Ergonomia aplicada ao trabalho: o manual técnico da máquina humana. Belo Horizonte: Ergo, 1995.v.1. 353p.

DUL, J.; WEERDMEESTER, B. Ergonomics for beginners - a quick reference guide. London: Taylor e Francis, 1994. 133p.

FIEDLER, N. C. et al. Avaliação da carga de trabalho físico exigida em operações da colheita florestal. Revista Árvore, v.22, p.535-543, 1998.

FIEDLER, N. C. et al. Análise de posturas na colheita florestal. Revista Árvore, v.23, p.435-441, 1999.

GOMES, J. F. Ergonomia do objeto: sistema técnico de leitura ergonômica. São Paulo:

Escrituras, 2003.
IIDA, I. Ergonomia; projeto e produção. São Paulo: Edgard Blucher, 1990. 465p.

INSTITUTO NACIONAL DE METROLOGIA Avaliação da conformidade. INMETRO. 2005. Disponível em: <http://www.inmetro.gov.br> Acesso em: 02 mar. 2005.

INSTITUTO NACIONAL DE TECNOLOGIA - INT Manual de aplicação dos dados antropométricos - Ergokit. Rio de Janeiro: 1995. CD-ROM.

INSTITUTO NACIONAL DE TECNOLOGIA - INT. Pesquisa antropométrica e biomecânica dos operários da indústria de transformação. Rio de Janeiro: 1988. 128p.

PANERO, J.; ZELNIK, M. Dimensionamento humano para espaços interiores. Barcelona: Gustavo Guili, 2002. 320p.

SILVA, K. R. et al. Análise de fatores ergonômicos em marcenarias no município de Viçosa, MG. Revista Árvore, v.25, p.317-325, 2001. 